\title{
Problem-Based Learning Environment In Basic Computer Course: Pre-Service Teachers' Achievement And Key Factors For Learning
}

Akın Efendioglu, Ph.D., Cukurova University, Turkey

\begin{abstract}
This experimental study aims to determine pre-service teachers' achievements and key factors that affect the learning process with regard to problem-based learning (PBL) and lecture-based computer course ( $L B C C)$ conditions. The research results showed that the pre-service teachers in the PBL group had significantly higher achievement scores than those in the LBCC group. Moreover, challenging, creativity, cognitive and affective attainments, and group aspects are regarded as positive learning keys in the PBL group; by contrast, in the LBCC group, the ease of learning and effective learning are found as positive learning keys, while superficial learning and adverse affective aspects are negative learning keys. Finally, these findings are discussed in terms of pre-service teachers' learning and skills and also the learning approaches used in the study.
\end{abstract}

Keywords: Problem-Based Learning; Lecture-Based Computer Course; Teacher Education; Learning Keys

\section{THE STRUCTURE OF PROBLEM-BASED LEARNING}

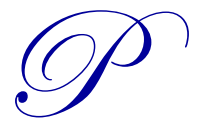

roblem-based learning (PBL) is an important practice that provides suitable learning environments for learners, in which they acquire complex problem-solving skills (PSS) by working with real-life problem situations. In today's world, learners' PSS and collaborative working skills are vital qualifications (Dochy, Segers, Van den Bossche, \& Gijbels, 2003; Engel, 1997; Gijbels, Dochy, Van den Bossche, \& Segers, 2005; Loyens, Gijbels, Coertjens, \& Côté, 2012; Spronken-Smith \& Harland, 2009). Moreover, especially in higher education, learners take courses with the aim of gaining profession-related skills (Loyens et al., 2013; Thomas, 2009). The PBL method originally was developed for medical education at McMaster University in Canada in the late 1960s (Barrows, 1994; Gijbel et al., 2005; Parton \& Bailey, 2008). Furthermore, according to Schmidt (1993), PBL is compatible with John Dewey's empiricism and Jerome Brunner's discovery learning approaches, which are the basic ideas of constructivism. In this respect, PBL shares similar characteristics with the constructivist approach (Stefanou et al., 2013). Barrows (1994, 1996), Gijbel et al. (2005), and Reynolds and Hancock (2010) describe the following six PBL characteristics. (1) Learning is student-centered: students should take responsibility for learning and also actively engage in the learning process through real experiences, meaning that they are able to use all their senses for learning. (2) Learning occurs in small student groups: a small student group should have five to nine members. In the group, students can perform in-depth problem solving with different group member perspectives. (3) Teachers act as facilitators or student guides: at McMaster University, the teacher's facilitator role is much like that of a tutor (Barrows, 1996). (4) Problems form the organizing focus and stimulus for learning: The problem is presented to students in different ways, such as written papers, computer simulations, video or audio recorders. (5) Problems are vehicles for the development of problem-solving skills: Learners work on the problems and make decisions to solve them. Moreover, they gain experience and learn different strategic approaches related to the main question of how the problem can be solved. (6) New information is acquired through self-directed learning: Learners regulate their problem-solving strategies and solutions based on their own experiences. 


\section{KEY CONCEPTS AND RECENT PBL RESEARCH}

The PBL approach and its effects on learning have been analyzed in several studies in the fields of natural science and social science. These studies have examined different PBL variables, such as self-regulated or directed learning, conceptual understanding, motivational aspects, critical thinking, and real-life situations (Dochy et al., 2003; Gallgher, 1997; Mercier \& Frederiksen, 2007; Pedersen, 2003; Stefanou et al., 2013; Sungur \& Tekkaya, 2006; Thomas, 2009; Yew \& Schmidt, 2009). In PBL environments, learners utilize prior feedback to assess their work, and thus, they arrange their problem-solving approaches in terms of their own goals (self-regulated or directed learning). In this process, students can understand the concept's core meaning by examining prior misconceptions; furthermore, as in Bruner's discovery learning process, they have recognized why the concept does not match their previous tentative conclusions (conceptual understanding). On the other hand, learners' individual learning efforts and awareness, i.e., their ability to manage tasks themselves in PBL environments, may positively awaken their affective characteristics and increase motivation (motivational aspects). Moreover, learners' reasonable reflective thinking (critical thinking see review of Ennis, 1962) to decide "what to believe and do" $(\mathrm{Ku}, 2009)$ is also related to these motivational aspects. Furthermore, there are many advantages to using real-life problem situations in PBL environments: (a) they are related to learners' professions; (b) they direct learners to perform their own research; (c) they require active learner participation; and (d) they provide remarkable learning environments for students (real-life situation).

Since Barrow first published his PBL theories, numerous PBL studies have been conducted. Furthermore, in the last decade, PBL research has been published in journals in world-class databases such as Science DirectWiley, Taylor \& Francis, and SAGE, which focus on medicine (see McLoughlin \& Darvill, 2007; Roberts \& Mitchell, 2005; Rogal \& Snider, 2008; Rowan et al., 2007), social sciences (Bozic \& Williams, 2011; De Simone, 2008; Dunlap, 2005; Lozano et al., 2012; Pearson et al., 2007; Pourshafie, Murray-Harvey, 2013), and sciences (Araz \& Sungur, 2007; Carrio et al., 2011; Pepper, 2010; Sungur, Tekkaya, \& Geban, 2006), respectively. In almost all of this research, the PBL approach is used as a method to provide effective learning and develop beneficial learning practices, such as self-direction, inquiry, meaningful learning, and conceptual understanding.

\section{COMPUTERS, PRE-SERVICE TEACHER TECHNOLOGICAL NEEDS, AND PBL}

Over the past thirty years, the importance of computers in human life has increased, leading to changes in almost all research areas (social sciences, sciences, and medical sciences) and our daily lives. Moreover, computer innovations have also changed the education system worldwide, introducing a new concept in academic literature: information communication technologies (ICTs). According to the Organization for Economic Co-operation and Development (OECD), ICT is currently one of the most important aspects in education and will remain so in the future (OECD, 2013). The question "How should ICT be used in an education system?" introduced new ways for teachers to use their ICT knowledge and skills in classroom instruction and to effectively perform their professional responsibilities. Furthermore, an International Society for Technology in Education (ISTE) report (2008) suggests "teachers continuously improve their professional practice, model lifelong learning, and exhibit leadership in their school and professional community by promoting and demonstrating the effective use of digital tools and resources." Additionally, teachers' confidence regarding ICT classroom use is considered as one of the crucial aspects (European Commission, 2013, p.19). Pre-service teachers' ICT classroom use depends on the skills they have gained during their in-service school experiences (Cuckle \& Clarke, 2002; Wedman \& Diggs, 2001). Eventually, ICT should integrate teacher education curricula and pre-service teacher training processes for effective instruction (Russell, Bebell, O'Dwyer, \& O'Connor, 2003).

Recent research by Mueller et al. (2008) aimed to determine the discriminating factors between teachers who fully integrate ICT in the classroom and those who do not. The study results illustrate that computer-related experiences, such as positive teaching experiences, training, and motivation, are significant variables in their classroom use of ICT. Moreover, the results of a review study by Mumtaz (2000) showed that teachers' formal computer training backgrounds significantly affected their decisions regarding ICT classroom use. In this context, computer courses have been implemented in teacher training curricula worldwide to develop pre-service teachers' ICT skills. However, it is not possible to meet pre-service teacher requirements for ICT-based skills and qualifications with traditional lecture-based methods. Lecture-based courses include three basic steps that Reynolds 
and Hancock (2010) have defined as introduction, presentation of information, and end of lesson. Lecture-based computer courses are slightly different from other lecture-based instruction in terms of its structure. Essentially, the lecturer starts with an introduction, presents the information, allows student application of information-related sample issues on their computers, and ends the lesson. In this respect, lecture-based courses obstruct student creativity, problem-solving skills (Hsieh \& Knight, 2008) and ICT skills. To eliminate these negative outcomes and to effectively enhance student ICT skills, PBL approaches may be used in computer courses. Although most PBL research has used computers as technological learning tools to facilitate teaching and learning processes (see Dunlap, 2005; Kim \& Pedersen, 2011; Raes, Schellens, De Weyer, \& Vanderhoven, 2012), there have been quite a few studies in recent years examining PBL-based approaches to computer courses (see Baturay \& Bay, 2010; Warren, Dondinger, McLeod, \& Bigenho, 2012). However, none of these studies applied to pre-service teachers. While Warren et al. (2012) focused on using PBL and 3-D computer game strategies in course design, Baturay and Bay (2010) used an experimental design for distance education. The present research may be the first PBL-based experimental study using both qualitative and quantitative approaches to provide and determine pre-service teacher ICT skills.

\section{PURPOSE AND RESEARCH QUESTIONS}

In the $21^{\text {th }}$ century, given the importance of teachers' ICT skills, teacher training curricula have been redesigned to incorporate technological innovations. Computer courses have been applied in teacher training programs to provide effective teacher training with regard to technological innovations. However, it may be impossible to produce technologically innovative teachers through lecture-based computer courses. Pre-service teachers' acquisition of ICT knowledge and rules may not be sufficient for them to use ICT in solving instructional problem situations. For effective teaching and learning, pre-service teachers need to solve real-life instructional problems, which they will encounter in classrooms. Thus, the aim of the present study is to determine pre-service teachers' learning outcomes in terms of academic achievement and key learning factors. The research questions are as follows:

- Is there a significant difference in academic achievement between pre-service students in PBL and LBCC groups?

- What are pre-service teachers' views regarding the PBL and LBCC approaches as they relate to learning outcomes, individual outcomes, individual computer skills, and the learning process?

\section{METHOD}

During the spring semester of 2013, the present study was conducted in a basic computer course taken by primary school pre-service teachers in the faculty of education. There were 187 pre-service teachers who took the course. The study sample $(\mathrm{n}=127)$ was randomly selected. Furthermore, these pre-service teachers were randomly divided into two groups. The present research used an experimental design, including a pre- and post-test group. In the first group, the PBL approach was used, and the group was named "Group PBL." In the second group, the LBCC approach was used, and the group was named "Group LBCC." At the end of the research process, the interviews were conducted with 12 randomly selected pre-service teachers; half were from Group PBL, and half were from Group LBCC. Details of the study research design are given in Table 1.

Table 1. Research design

\begin{tabular}{|c|c|c|c|c|}
\hline Groups & $\begin{array}{c}\text { pre-Achievement } \\
\text { Test (pre-AT) }\end{array}$ & Research process & $\begin{array}{l}\text { post-Achievement } \\
\text { Test (post-AT) }\end{array}$ & Interview \\
\hline PBL & $\mathrm{X}_{1.1}$ & $\begin{array}{l}\text { Pre-service teachers worked on a } \\
\text { problem into a small group (each group } \\
\text { has } 6 \text { or } 7 \text { members). }\end{array}$ & $\mathrm{X}_{1.2}$ & \multirow{2}{*}{$\begin{array}{l}\text { Interview questions the } \\
\text { pre-service teachers were } \\
\text { asked }\end{array}$} \\
\hline LBCC & $\mathrm{X}_{1.1}$ & $\begin{array}{l}\text { Lecturer presented course subjects to pre- } \\
\text { service students. After that, pre-service } \\
\text { students worked on similar sample } \\
\text { subjects on computer individually. }\end{array}$ & $\mathrm{X}_{1.2}$ & \\
\hline
\end{tabular}

$\mathrm{X}_{1.1}$ : Shows the pre-AT that applied to pre-service teachers before the research process started. $\mathrm{X}_{1.2}$ : Shows the post-AT that applied to pre-service teachers at the end of the research process. 


\section{Participants}

Group LBCC includes 67 pre-service teachers in the same department and at the same level, but chosen randomly from two classes. Furthermore, 42 pre-service teachers are female (62.7\%), and 25 are male (37.3\%); their ages range from 17 to 20 years $(\bar{x}=17.85$; sd=0.87). In Group PBL, there are 60 pre-service teachers chosen from the same two classes as those in Group LBCC. Of the 60 pre-service teachers, 36 are female $(60 \%)$, and 24 are male (40\%); their ages range from 17 to 21 years $(\bar{x}=17.92$; $\mathrm{sd}=0.91)$.

\section{Research Content (Subjects)}

The present research was conducted on a basic computer course. Throughout the study, the basic MS Excel features and 23 different Excel functions listed in Table 2 were used.

Table 2. List of MS Excel functions

\begin{tabular}{clcl}
\hline Number & \multicolumn{1}{c}{ Name of function } & Number & \multicolumn{1}{c}{ Name of function } \\
\hline 1 & SUM( ) & 13 & LARGE( ) \\
2 & AVARAGE( ) & 14 & SMALL( ) \\
3 & SUMSQ( ) & 15 & AND( ) \\
4 & SQRT( ) & 16 & OR( ) \\
5 & FACT( ) & 17 & RIGHT( ) \\
6 & MIN( ) & 18 & SEFT( ) \\
7 & MAX( ) & MID( ) \\
8 & COUNTBLANK( ) & 19 & ISBLANK( ) \\
9 & COUNTIF( ) CONCATENATE( ) \\
10 & COUNTA( ) & 21 & \\
11 & COUNT( ) & 22 & \\
\hline
\end{tabular}

\section{Procedure}

The present research was completed within seven weeks. In the following sections, a detailed explanation is given of the research procedures that were applied in both Groups PBL and LBCC.

\section{Procedure in Group PBL Introductory Seminar}

The PBL approach was used in this group. A two-hour introductory course was held for pre-service teachers before the research process began. The aim of the introductory seminar was to provide pre-service teachers with the critical structure of the course subjects. Within the scope of the introductory course, the general structure of MS Excel software and five different Excel functions; each of which was selected from mathematical, statistical, logical, textual, and knowledge function categories were explained in detail to the pre-service teachers. All functions that were presented to pre-service teachers were distinct from the functions the research subjects were given in section 5.2. During the introductory seminar, following the lecturer's presentation, pre-service teachers individually applied samples on computers, and they asked the lecturer questions about the functions. Additionally, participants were divided into ten different groups, each with six or seven members. After the introductory seminar, the lecturer explained the steps for the PBL and the way participants should work during the research process.

\section{Research Procedure}

Each week (a total of four course hours) the lecturer presented a problem situation to the participants at the beginning of class. Then, each group spent two course hours working on the problem separately and trying to draft a problem-solving plan. Moreover, each group met throughout the week to develop the draft problem-solving plan and find a solution. For two hours at week's end, each group projected their solutions to the other groups in the computer laboratory, and they gave a problem report to the lecturer. The following is a sample problem situation that was presented to the groups: 
"A math teacher takes four exams and gives two individual projects to evaluate students' academic achievement during a semester. Additionally, the teacher wants to give to students a prize as reinforcement in the mid-term. There are two types of prizes: (a) the first one is a special pencil set, and (b) the second is a pencil. The teacher uses a formulation to determine which prize is suitable for students. According to this formulation, if the total student score (30\% of the first exam, 30\% of the second exam, and 40\% of the first project score) is higher than 80, he/she takes " $a$ "; if her/his score is between 70 and 80 he/she takes " $b$ "; if her/his score is less than 70, he/she should attend a math support program. Consequently, the teacher will prepare an MS Excel table to calculate the proper student results. How can the teacher solve this evaluation problem using an MS Excel table and functions?

\section{Procedure in Group LBCC}

Each week (a total of four course hours), the lecturer gave a presentation to students and explained the structure of three functions, projecting several examples during the first two course hours. Then, students used computers to work individually on the samples, and they printed Excel documents during the last two course hours. Finally, students wrote a short report about their MS Excel documents.

\section{Data Collecting Tools}

The present research used two different data collecting tools. The tools' general structure and statistical analysis are given in the following sections.

\section{Academic Achievement Test (AT)}

There are 21 open-ended questions in AT. In the fifth question, there are three sub-questions. Moreover, in all of the questions, pre-service teachers are expected to write a proper and meaningful Excel function or a combination of proper functions. To score the items, criteria - such as (1) selecting correct function/s, (2) correct punctuation in function/s, (3) logical integrity, and (4) selecting correct cell/s-are used to provide objective evaluation of pre-service teacher papers. Consequently, a correct answer is given 5 points. According to reliability analysis of the AT, Cronbach's Alpha coefficient was calculated as 0.91 .

Interview Form (IF)

There are five open-ended questions in the interview form (IF). The comments of three experts with doctoral degrees were considered in IF question development. Moreover, another expert with a doctoral degree checked the questions in terms of their language structures and clarity. All interviews were conducted in the researcher's office and were recorded with an audio recorder. In the next phase, the researcher gave participants standardized names in the recorded transcripts (e.g., PBL-Student-1..., LBCC-Student-1..., etc.). Student interview transcripts were 42 pages in total. Then, two transcript copies were made, one that the researcher coded and the other that an independent expert with a doctoral degree coded. Following the coding process, an inductive content analysis method was applied. Additionally, according to the results of Miles and Huberman's (1994) inter-coder reliability analysis, the inter-coder reliability of the IF was 0.87 .

\section{FINDINGS}

\section{Academic Achievement of Pre-Service Teachers in Group PBL and Group LBCC}

The t-test is performed to determine the difference between the pre-AT scores of pre-service teachers in Group PBL and Group LBCC. The test results are given in Table 3.

Table 3. T-test results between pre-AT scores of the PBL and LBCC groups

\begin{tabular}{llccccc}
\hline \multicolumn{1}{c}{ Groups } & $\mathbf{N}$ & $\overline{\boldsymbol{x}}$ & $\mathbf{s d}$ & $\mathbf{d f}$ & $\mathbf{t}$ & $\mathbf{p}$ \\
\hline PBL & 60 & 0.40 & 1.25 & 125 & 6.325 & $0.000^{\mathrm{a}}$ \\
LBCC & 67 & 13.09 & 15.49 & & & \\
\hline $\mathrm{a} p<0.001$ & & &
\end{tabular}

${ }^{\mathrm{a}} \mathrm{p}<0.001$ 
According to Table 3, there is a significant difference between pre-service teachers in Group PBL and Group LBCC in favor of Group LBCC [ $\left.\mathrm{t}_{(125)}=6.325, \mathrm{p}<0.001\right]$. In addition, an analysis of covariance (ANCOVA) was conducted on the groups to determine whether there is any difference between the post-AT scores of pre-service teachers in Group PBL and Group LBCC. The analysis results are given in Table 4.

Table 4. ANCOVA results of the post-AT scores between the group PBL and group LBCC

\begin{tabular}{lcrrrr}
\hline \multicolumn{1}{c}{ Source } & Sum of squares & df & Mean square & \multicolumn{1}{c}{ f } & \multicolumn{1}{c}{ p } \\
\hline pre-AT & 154.215 & 1 & 154.215 & 0.341 & 0.560 \\
Group & 17728.915 & 1 & 17728.915 & 39.228 & $0.000^{\mathrm{a}}$ \\
Error & 56041.165 & 124 & 451.945 & & \\
Corrected total & 81796.127 & 126 & & & \\
\hline
\end{tabular}

${ }^{\mathrm{a} p}<0.001$

According to Table 4 , there is a meaningful difference between the groups in terms of post-AT scores [ $\mathrm{F}_{(1-}$ $\left.{ }_{124}=39.228, \mathrm{p}<0.001\right]$. Furthermore, a multiple comparison (Bonferroni) test is conducted to determine the difference between the groups. The test results are given in Table 5 .

Table 5. Test results of pairwise comparisons (Bonferroni)

\begin{tabular}{lcccc}
\hline \multicolumn{1}{c}{ Groups } & $\mathbf{N}$ & $\overline{\boldsymbol{x}}$ (means) & $\overline{\boldsymbol{x}}$ (means) $^{\mathbf{a}}$ & $\mathbf{p}$ \\
\hline PBL & 60 & 72.61 & 71.95 & \multirow{2}{*}{$0.000^{\mathrm{b}}$} \\
LBCC & 67 & 44.17 & 44.76 & \\
\hline
\end{tabular}

${ }^{\mathrm{a}}$ Corrected means; ${ }^{\mathrm{b}}$ Adjustment for multiple comparison (Bonferroni) $\mathrm{p}<0.001$

The results given in Table 5 show that there is a meaningful group difference in favor of group PBL $(\mathrm{p}<0.001)$. Moreover, the adjusted mean post-AT test scores of Group PBL's pre-service teachers are higher than those of Group LBCC's pre-service teachers.

\section{Group PBL Qualitative Findings}

Interviews were conducted with six pre-service teachers from Group PBL. The themes, sub-theme(s) and codes obtained from the interview transcripts are shown in Table 6.

In Table 6, there are four themes and two sub-themes in the "individual attainments" theme. In the "challenging" theme, four codes are found that relate to requiring more time, group participation, and needing to conduct further research. Additionally, it is determined that there are three codes within the "creativity" theme and two different sub-themes within the "individual attainments" theme. The first sub-theme, "cognitive attainments," includes four codes that clearly refer to the pre-service teachers' cognitive development. The second sub-theme, "affective attainments," includes four codes that relate to the requisite pre-service teacher characteristics to achieve effective learning environments. These characteristics are mentioned in the results of prior PBL research. Lastly, in the "group aspects" theme, three codes, likely consequences of small group training, are found. 
Table 6. Results of the qualitative analysis of pre-service teachers in the group PBL

\begin{tabular}{lll}
\hline & \multicolumn{1}{c}{ Code(s) } & f \\
\hline & Theme(s) & 5 \\
Challenging & To require more time require group participation & 5 \\
& To find mutual solutions & 4 \\
& To perform research orientation & 3 \\
\hline \multirow{2}{*}{ Creativity } & To be open to new ideas & 4 \\
& To handle the problem from different angles & 4 \\
\hline Individual attainments & To imagine various solutions & 2 \\
\hline & & 5 \\
Cognitive attainments & Deep learning & 5 \\
& Meaningful learning & 4 \\
& Permanent learning & 4 \\
Affective attainments & Knowledge customization & 6 \\
& More self-confidence & 6 \\
& More self-efficacy & 5 \\
Group aspects & Intrinsic motivation & 3 \\
& More self-awareness & 4 \\
\hline
\end{tabular}

\section{Group LBCC Qualitative Findings}

The interview results for six pre-service teachers from Group LBCC are shown in Table 7.

Table 7. Results of the qualitative analysis of pre-service teachers in the Group LBCC

\begin{tabular}{lll}
\hline \multicolumn{1}{c}{ Theme(s) } & \multicolumn{1}{c}{ Code(s) } & f \\
\hline \multirow{2}{*}{ Ease of learning } & Less effort & 5 \\
& Fast learning & 5 \\
& Simplicity & 4 \\
\hline \multirow{2}{*}{ Superficial learning } & To fail to recall knowledge & 4 \\
& To have difficulty in customizing knowledge & 4 \\
\hline Effective learning & To have difficulty linking knowledge & 3 \\
\hline \multirow{2}{*}{ Adverse affective aspects } & Meaningful learning & 2 \\
& To feel inadequacy & 4 \\
\hline
\end{tabular}

In Table 7, there are four different themes. The first theme, "ease of learning," includes three codes. At first glance, all of these codes seem to have a positive effect on learning (e.g., less effort, fast learning, and simplicity). Additionally, the second theme, "superficial learning," consists of three codes that have adverse effects on the learning process. In contrast, the "effective learning" theme, which contains a "meaningful learning" code, has a positive impact on learning; however, its frequency is very low. Lastly, in the "adverse affective aspects" theme, which includes "to feel inadequacy" and "to feel ineffectiveness" codes, more than half of the pre-service teachers state that they have negative feelings about learning at the end of the study.

\section{DISCUSSION AND CONCLUSION}

In this section, both qualitative and quantitative results are discussed to form a general framework and emphasize the study's conclusions. Learners' academic achievements have been discussed in terms of its importance in higher education. In the present study, the learning outcome perspectives are discussed with the strength of quantitative and qualitative analysis techniques under PBL and LBCC conditions.

According to the t-test results of the pre-AT scores of the pre-service teachers in both Group PBL and Group LBCC, Group LBCC's pre-service teachers had significantly higher scores $(\bar{x}=13.00)$ than those of Group $\operatorname{PBL}(\bar{x}=0.40)$. However, at the end of the research process, the post-AT ANCOVA results of Group PBL's preservice teachers showed that they had significantly higher scores $(\bar{x}=72.61)$ than those of Group LBCC $(\bar{x}=44.17)$. It 
is evident that the PBL methods used in this basic computer course have highly positive effects on learning outcomes. In this context, the quantitative results of Sungur, Tekkaya and Geban's (2006) study favor the present study's findings. Moreover, according to the qualitative results of the present study, the "more self-confidence" and "intrinsic motivation" codes (see the "affective attainments" sub-theme of the "individual attainments" theme in Table 6) and the "to feel inadequacy" and "to feel ineffectiveness" codes (see the "adverse affective aspects" theme in Table 7) reflect learners' motivations. Thus, these motivational characteristics may positively affect the learners' actual achievements in Group PBL, while they may negatively affect Group LBCC. These findings agree with the results of Meyer, McClure, Walkey, Weir, and McKenzie's (2009) structural equation modeling study, which showed that motivational aspects were strongly related to learners' actual achievement. Furthermore, these researchers described two types of actual achievement: high achievement (doing my best) and low achievement (doing just enough). In this context, considering PBL and LBCC methods and procedures, the "to require more time," "to require group participation," "to find mutual solutions," and "to perform research orientation" codes in the "challenging" theme (see Table 6) may closely relate to high achievement (doing my best), while the "less effort," "fast learning" and "simplicity" codes in the "ease of learning" theme may closely relate to low achievement (doing just enough).

Additionally, the codes obtained from Group PBL, "deep learning," "meaningful learning," "permanent learning," and "knowledge customization" in the "cognitive attainments" theme (see Table 6), and the codes obtained from Group LBCC, "to fail recall knowledge," "to have difficulty in customizing knowledge," and "to have difficulty linking knowledge" in the "superficial learning" theme (see Table 7), support these achievement correlations. In contrast, two pre-service teachers in Group LBCC stated that they had learned the subjects meaningfully (see "effective learning" theme in Table 7). These statements conflict with those from other preservice teachers in the same group. However, it was determined that they are experienced pre-service teachers in terms of using MS Excel functions. In this regard, it is evident that these views may arise from the situation's typical results.

Apart from the aforementioned comments, a study conducted by Diseth and Martinsen (2003) focused on the relation between deep, strategic, and surface learning approaches and academic achievement. They found a direct relation between the learning approaches and academic achievement. Thus, in the present study, both codes in the "challenging" and "individual attainments" themes in Group PBL (see Table 6) and the codes in the "superficial learning" and "adverse affective aspects" themes (see Table 7) in Group LBCC correspond with their study results.

On the other hand, according to qualitative results of Group PBL, the codes "to require group participation," "to perform research orientation," and "to find mutual solutions" in the challenging theme are emphasized as PBL goals in many studies (Barron et al., 1998; Hmelo-Silver, 2004). Additionally, the "knowledge customization" code in the "cognitive attainments" sub-theme may be related to self-directed/regulated learning. According to the definition of self-directed/regulated learning, learners with previous experience are able to adapt their problem-solving approaches, strategies or skills to various problematic situations. In this regard, knowledge customization is only possible if they learn the subjects deeply and meaningfully; therefore, the codes "deep learning," "meaningful learning," and "permanent learning" (see Table 6) may provide evidence of this knowledge customization because, according to the studies of Azer (2009), Gijbels et al. (2005), Loyens et al. (2013), and Mennin (2007), the concept of self-directed/regulated learning is one of the basic parts or outcomes of the PBL approach.

In the present study, the "creativity" theme is one of the most interesting results; Mayer stated that creativity is the "creation of new and useful products including ideas as well as concrete objects" (Zeng, Proctor, \& Salvendy, 2011). In this regard, there are three theme codes: "to be open new ideas," "to handle the problem from different angles," and "to imagine various solutions." Studies that discuss the creativity concept state that creativity has two criteria: novelty and appropriateness (Alfonso-Benlliure, Meléndez, \& García-Ballesteros, 2013; Zeng, Proctor, \& Salvendy, 2011). Additionally, creativity may be possible if learners approach a problem from different perspectives (Csikszentmihalyi \& Getzels, 1971), as stated in the "to handle the problem from different angles" code; have imagination (Badran, 2007; Karwowski \& Soszynski, 2008), as stated in the "to imagine various solutions" code; and consider new ideas with encouragement and support (Craft, 2003), as stated in the "to be open 
to new ideas" code. However, because learners' creativity may be enhanced in small group settings, "creativity" and "group aspects" themes also have to be discussed.

In a study conducted by Moore (2000), the group creativity and learners' individual creativity were compared, and the results showed that learners had higher creativity scores when they worked in groups than when they worked individually. Furthermore, he accepted that high cohesion and high knowledge variables were indicators of creativity. Similarly, Karwowski and Soszynski (2008) stated that group activities support learners' creativity. In the present study, "cooperation" and "communication" codes in the "creativity" theme may show evidence of high cohesion. Additionally, the "to find mutual solutions" code in the "challenging" theme may relate to high knowledge.

There are two main conclusions in the present study. The first one relates to the PBL approach. Apart from prior research, it is found that the PBL approach supports learners' affective and cognitive constructs in a positive manner and favors learners' creative problem-solving skills. However, this approach is rarely encountered in literature in terms of computer course content. This research gap is far more significant in terms of pre-service teachers' professional development. Pre-service teachers should be able to solve problems that they will encounter in classrooms in their professional work life in the near future, and in this process, they may use creativity skills. The second conclusion relates to learning in PBL and LBCC conditions. On the one hand, the research results clearly illustrate that LBCC is not adequate in providing the necessary skills and meaningful learning for the preservice teachers in terms of actively engaging them in the learning process and constructing effective and meaningful learning; on the other hand, it is evident that PBL supports learners by implementing concrete learning motivation, encouraging affective and cognitive attainments, and challenging learners. Additionally, in computer courses, providing active participation in the learning process is not possible by solely providing pre-service teachers with lecturer examples on computers. Lecturers should give learners problems that have different structures than the ones that the lecturer presents in class. Thus, the PBL process goes beyond the ordinary learning process, which is described as repeating the lecturer's examples on the computer, and provides learners with real active participation.

\section{LIMITATIONS}

The present research has two primary limitations. First, the present study was conducted on the subject of MS Excel functions in a basic computer course. Second, the evaluation of pre-service teachers in both Group PBL and Group LBCC was based on an achievement test with open-ended questions.

\section{AUTHOR INFORMATION}

Akın Efendioglu, Ph.D., has been working as Ph.D. Lecturer at Çukurova University, Faculty of Education in the department of Primary School Teaching for 14 years. I have been giving some courses as Basic Computer Skills, Introduction to Educational Sciences, Teaching and Learning Approaches, Measurement and Evaluation in Education, Scientific Research Methods, and Cognitive Load in Multimedia Learning Environments for undergraduate and post-graduate students at the department. I have several published articles and book chapters both national and international areas as well as congress. Additionally, I have been participating at several national and international scientific journals indexed in SSCI-ERIC databases as a reviewer. Akın Efendioglu, Ph.D., Cukurova University, Faculty of Education, Department of Primary School Teaching, 01330, Turkey. Email: eakin@cu.edu.tr

\section{REFERENCES}

Alfonso-Benlliure, V., Meléndez, J. C., \& García-Ballesteros, M. (2013). Evaluation of a creativity intervention program for preschoolers. Thinking Skills and Creativity, 10, 112-120.

Araz, G. \& S. Sungur (2007). The interplay between cognitive and motivational variables in a problem-based learning environment. Learning and Individual Differences, 17(4), 291-297.

Azer, S. A. (2009). Problem-based learning in the fifth, sixth, and seventh grades: Assessment of students' 
perceptions. Teaching and Teacher Education, 25(8), 1033-1042.

Badran, I. (2007). Enhancing creativity and innovation in engineering education. European Journal of Engineering Education, 32(5), 573-585.

Barron, B. J., Schwartz, D. L., Vye, N. J., Moore, A., Petrosino, A., Zech, L., et al. (1998). Doing with understanding: Lessons from research on problem-and project-based learning. Journal of the Learning Sciences, 7(3-4), 271-311.

Barrows, H. S. (1994). Practice-based learning: Problem-based learning applied to medical education. Springfield: Southern Illinois University Press.

Barrows, H. S. (1996). Problem- based learning in medicine and beyond: A brief overview. New Directions for Teaching and Learning, 68, 3-12.

Baturay, M. H., \& Bay, O. F. (2010). The effects of problem-based learning on the classroom community perceptions and achievement of web-based education students. Computers \& Education, 55(1), 43-52.

Bozic, N., \& Williams, H. (2011). Online problem-based and enquiry-based learning in the training of educational psychologists. Educational Psychology in Practice, 27(4), 353-364.

Carrio, M., Larramona, P., Baos, J. E., \& Perez, J. (2011). The effectiveness of the hybrid problem-based learning approach in the teaching of biology: a comparison with lecture-based learning. Journal of Biological Education, 45(4), 229-235.

Craft, A. (2003). The limits to creativity in education: Dilemmas for the educator. British Journal of Educational Studies, 51(2), 113-127.

Csikszentmihalyi, M., \& Getzels, J. (1971). Discovery-oriented behavior and the originality of creative products: a study with artists. Journal of Personality and Social Psychology, 19(1), 47-52.

Cuckle, P., \& Clarke, S. (2002). Mentoring student-teachers in schools: views, practices and access to ICT. Journal of Computer Assisted Learning, 18(3), 330-340.

De Simone, C. (2008). Problem- Based Learning: a framework for prospective teachers' pedagogical problem solving. Teacher Development, 12(3), 179-191.

Diseth, A., \& Martinsen, O. (2003). Approaches to learning, cognitive style, and motives as predictors of academic achievement. Educational psychology, 23(2), 195-207.

Dochy, F., Segers, M., Van den Bossche, P., \& Gijbels, D. (2003). Effects of problem-based learning: a metaanalysis. Learning and Instruction, 13(5), 533-568.

Dunlap, J. C. (2005). Changes in Students' Use of Lifelong Learning Skills During a Problem- based Learning Project. Performance Improvement Quarterly 18(1), 5-33.

Engel, C. E. (1997). Not just a method but a way of learning. In D. Boud \& G. Feletti (Eds.), The challenge of problem-based learning (2 ${ }^{\text {nd }}$ ed., pp. 17-25). London: Kogan Page.

Ennis, R. H. (1962). A concept of critical thinking. Harvard Educational Review, 32(1), 81-111.

European Commission. (2013). Survey of Schools: ICT in Education. (ISBN 978-92-79-28121-1). Luxembourg: Publications Office of the European Union.

Gallagher, S. A. (1997). Problem-based learning: Where did it come from, what does it do, and where is it going? Journal for the Education of the Gifted, 20(4), 332-362.

Gijbels, D., Dochy, F., Van den Bossche, P., \& Segers, M. (2005). Effects of problem-based learning: A metaanalysis from the angle of assessment. Review of Educational Research, 75(1), 27-61.

Hmelo-Silver, C. E. (2004). Problem-based learning: What and how do students learn? Educational Psychology Review, 16(3), 235-266.

Hsieh, C., \& Knight, L. (2008). Problem-based learning for engineering students: An evidence-based comparative study. The Journal of Academic Librarianship, 34(1), 25-30.

ISTE. (2008). Advancing Digital Age Teaching. Retrieved August 10, 2013, from https://www.iste.org/docs/pdfs/nets-t-standards.pdf?sfvrsn=2

Karwowski, M., \& Soszynski, M. (2008). How to develop creative imagination? Assumptions, aims and effectiveness of Role Play Training in Creativity (RPTC). Thinking Skills and Creativity, 3(2), 163-171.

Kim, H. J., \& Pedersen, S. (2011). Advancing young adolescents' hypothesis-development performance in a computer-supported and problem-based learning environment. Computers \& Education, 57(2), 1780-1789.

Ku, K. Y. L. (2009). Assessing students' critical thinking performance: Urging for measurements using multiresponse format. Thinking Skills and Creativity, 4(1), 70-76.

Loyens, S. M., Gijbels, D., Coertjens, L., \& Côté, D. J. (2013). Students' approaches to learning in problem-based learning: Taking into account professional behavior in the tutorial groups, self-study time, and different 
assessment aspects. Studies in Educational Evaluation, 39, 23-32.

Lozano et al. (2012). Problem-based learning supported by semantic techniques, Interactive Learning Environments, DOI: $10.1080 / 10494820.2012 .745431$

McLoughlin, M., \& Darvill, A. (2007). Peeling back the layers of learning: A classroom model for problem-based learning. Nurse Education Today, 27(4), 271-277.

Mennin, S. (2007). Small-group problem-based learning as a complex adaptive system. Teaching and Teacher Education, 23(3), 303-313.

Meyer, L. H., McClure, J., Walkey, F., Weir, K. F., \& McKenzie, L. (2009). Secondary student motivation orientations and standards-based achievement outcomes. British Journal of Educational Psychology, 79, 273-293.

Miles, M.B. \& Huberman, A.M. (1994). Qualitative data analysis, ( $2^{\text {nd }}$ ed.). Thousand Oaks, CA: Sage Publications.

Moore, R. M. (2000). Creativity of small groups and of persons working alone. Journal of Social Psychology, $140(1), 142-143$.

Mueller, J., Wood, E., Willoughby, T., Ross, C., \& Specht, J. (2008). Identifying discriminating variables between teachers who fully integrate computers and teachers with limited integration. Computers \& Education, 51(4), 1523-1537.

Mumtaz, S. (2000). Factors affecting teachers' use of information and communications technology: a review of the literature. Journal of Information Technology for Teacher Education, 9(3), 319-342.

OECD (2013). Trends Shaping Education 2013. OECD Publishing. doi: 10.1787/trends_edu-2013-en

Parton, G., \& Bailey, R. (2008). Problem- based learning: a critical rationalist perspective. London Review of Education, 6(3), 281-292.

Pearson, V., Wong, D. K. P., Ho, K., \& Wong, Y. (2007). Problem based learning in an MSW programme: A study of learning outcomes. Social Work Education, 26(6), 616-631.

Pedersen, S. (2003). Motivational Orientation in a Problem-Based Learning Environment. Journal of Interactive Learning Research, 14(1), 51-77.

Pepper, C. (2010). 'There's lot of learning going on but NOT much teaching!': student perceptions of Problem- Based Learning in science. Higher Education Research \& Development, 29(6), 693-707.

Pourshafie, T. and R. Murray-Harvey (2013). Facilitating problem-based learning in teacher education: getting the challenge right. Journal of Education for Teaching, 39(2), 169-180.

Raes, A., Schellens, T., De Weyer, B., \& Vanderhoven, E. (2012). Scaffolding information problem solving in webbased collaborative inquiry learning. Computers \& Education, 59(1), 82-94.

Reynolds, J. M., \& Hancock, D. R. (2010). Problem-based learning in a higher education environmental biotechnology course. Innovations in Education and Teaching International, 47(2), 175-186.

Roberts, D., \& Mitchell, D. (2005). Problem-based learning in nurse education: An unexpected problem for students with dyslexia. Nurse Education in Practice, 5(6), 328-332.

Rogal, S. M., \& Snider, P. D. (2008). Rethinking the lecture: The application of problem based learning methods to atypical contexts. Nurse Education in Practice, 8(3), 213-219.

Rowan, C. J., McCourt, C., Bick, D., \& Beake, S. (2007). Problem based learning in midwifery-the teachers perspective. Nurse Education Today, 27(2), 131-138.

Russell, M., Bebell, D., O'Dwyer, L., \& O'Connor, K. (2003). Examining teacher technology use: Implications for preservice and inservice teacher preparation. Journal of Teacher Education, 54(5), 297-310.

Schmidt, H. G. (1993). Foundations of Problem-Based Learning - Some Explanatory Notes. Medical Education, $27(5), 422-432$.

Spronken-Smith, R., \& Harland, T. (2009). Learning to teach with problem-based learning. Active Learning in Higher Education, 10(2), 138-153.

Stefanou, C., Stolk, J. D., Prince, M., Chen, J. C., \& Lord, S. M. (2013). Self-regulation and autonomy in problemand project-based learning environments. Active Learning in Higher Education, 14(2), 109-122.

Sungur, S., \& Tekkaya, C. (2006). Effects of problem-based learning and traditional instruction on self-regulated learning. Journal of Educational Research, 99(5), 307-317.

Sungur, S., Tekkaya, C., \& Geban, O. (2006). Improving achievement through problem-based learning. Journal of Biological Education, 40(4), 155-160.

Thomas, I. (2009). Critical thinking, transformative learning, sustainable education, and problem-based learning in universities. Journal of Transformative Education, 7(3), 245-264. 
Warren, S. J., Dondinger, M. J., McLeod, J., \& Bigenho, C. (2012). Opening The Door: An evaluation of the efficacy of a problem-based learning game. Computers \& Education, 58(1), 397-412.

Wedman, J., \& Diggs, L. (2001). Identifying barriers to technology-enhanced learning environments in teacher education. Computers in Human Behavior, 17(4), 421-430.

Yew, E. H., \& Schmidt, H. G. (2009). Evidence for constructive, self-regulatory, and collaborative processes in problem-based learning. Advances in Health Sciences Education, 14(2), 251-273.

Zeng, L. A., Proctor, R. W., \& Salvendy, G. (2011). Can Traditional Divergent Thinking Tests Be Trusted in Measuring and Predicting Real-World Creativity? Creativity Research Journal, 23(1), 24-37. 